\title{
ANALISIS KEBIJAKAN PENGENDALIAN URBANISASI KOTA BERASTAGI KABUPATEN KARO SUMUT
}

\author{
Oleh : \\ Putri Anne Br Sembiring 1) \\ Matius Bangun 2) \\ Universitas DarmaAgung, Medan ${ }^{1,2)}$ \\ E-mail: \\ $\frac{\text { Putrisembiring.id@gmail.com }}{{ }^{1)}}$
}

\begin{abstract}
ABSTRAK
This study aims at analyzing the factors driving and pulling the occurrence of urbanization in Berastagi and the efforts made by the Karo district government to control it. The method used is descriptive qualitative with primary data sources from interviews and field observations, while secondary data is from literary studies, social media and documentation. The data analysis used is the Delphi analysis to equalize the perceptions of the informants, the analysis of pull and support factors as well as policy analysis on efforts to control urbanization in the City of Berastagi.The conclusion from the results of this study is that the main driving factor for urbanites from their hometowns for those who are not married is shy to live in the village, while for those who are already married are limited employment opportunities in the village. The main draw factor for urbanites from the destination area is for those who do not have family, invite friends who are already in the city while those who are already married are looking for a new job. Efforts made by the Government in the Origin Region are Encouraging and Facilitating: Soft Loans, MSME Empowerment Program Assistance (especially Micro Enterprises) and Building Village Facilities through APBD. Efforts made by the Government in the urbanization destination of Berastagi City are to make a new settlement plan consisting of a. Agricultural Zone on Jl. Air (Column Monument towards Simpang Empat District); $b$. Office Zone On Jl. Djamin Ginting (from Tugu Kol to Kec. Kaban Jahe); . and c. Tourism Zone Jl. Djamin Ginting starting from the monument mejuah Juah towards Tahura).
\end{abstract}

Keywords: Urbanization, Berastagi City, Supporting Factors, Inhibiting Factors

\section{ABSTRAK}

Penelitian ini bertujuan untuk menganalisis fakto faktor pendorng dan Penarik terjadinya urbanisasi di Berastagi serta upaya upaya yang di lakukan Pemerintah kabupaten karo untuk pengendaliannya. Metode yang di kunakan adalah kualitatif diskriftif dengan sumber data primer dari hasil wawancara dan observasi lapangan sedangkan data sekunder dari studi litratur, media sosial dan dokumentasi. Analisis data yang di gunakan adalah analisis delphi untuk menyamakan persepsi dari informan, analisis faktor penarik dan pendoriong serta analisis kebijakan tentang upaya upaya pengendalian urbanisasi di Kota Berastagi. Adapun kesimpulan dari hasil penelitian ini adalah Faktor Pendorong utama urban dari daerah asala bagi yang Belum Berkeluarga adalah Malu Tinggal di Desa sedangkan bagi yang Sudah Berkeluarga adalah Terbatasnya Lapangan Kerja di Desa. Faktor Penarik utama urban dari daerah tujuan adalah bagi yang Belem Berkeluarga adalah Ajakakan teman yang sudah ada di kota sedangkan bagi yang Sudah Berkeluarga adalah Mencari Pekerjaan Baru. Upaya yang di lakukan Pemerintah di Daerah Asal adalah Mendorong dan Memfasilitasi : Pinjaman Lunak, Bantuan Program Pemberdayaan UMKM (khususnya Usaha Mikro) Dan Membangun Fasilitas desa melalui APBD. Upaya yang dilakukan Pemerintah di daerah tujuan urbanisasi Kota Berastagi adalah Membuat Rencana Pemukiman baru yang terdiri dari a. Zona Pertanian di Jl. Udara (Tugu Kol ke arah Kecamatan Simpang Empat); b. Zona Perkantoran 
Di Jl. Djamin Ginting (dari Tugu Kol menuju Kec. kaban Jahe); . dan c. Zona Pariwisata Jl. Djamin Ginting mulai Tugu mejuah Juah menuju Tahura).

\section{Kata Kunci : Urbanisasi, Berastagi, Faktor Pendorong, Fakto Penghambat}

\section{PENDAHULUAN \\ 1.1 Latar Belakang}

Kementerian PUPR melalui Direktat Jenderal (2016) : bahwa laju urbanisasi masyarakat dalam beberapa waktu terakhir cukup pesat. Di satu sisi, urbanisasi memiliki dampak positif bagi penyediaan tenaga kerja yang murah, namun di sisi lain potensial berdampak negatif bagi perkembangan wilayah perkotaan. Disadari bahwa kota merupakan tempat strategis yang menjadi tujuan urbanisasi di mana setiap penduduk untuk mencari pekerjaan dalam rangka meningkatkan kesejahteran dan kelayakan.

Berastagi yang adalah merupakan kota terbesar ke dua di Kabupaten Karo yang memiliki keunggulan di mana di samping kota yang penduduknya bermata pencaharian di sektor pertanian juga sebagai salah satu kota tujuan wisata di Sumatera Utara. Sektor pariwisata ini menjanjikan relatif lebih banyak kesempatan dan lapangan pekerjaan di bandingkan dengan pertanian. Jasa jasa pelayanan tersebut seperti seperti perhotelan, restouran, kuliner, travel, sovenir yang tidak dimiliki oleh sektor pertanian. Kelebihan kelebihan dari kota inilah yang menjadi daya tarik bagi penduduk yang tinggal di pedesaan khususnya sekitar kota Berastagi untuk bersaing memanfaatkan kesempatan di maksud dengan berpindah dari desa menuju kota Berastagi.

Sebagai dampak dari berpindahnya penduduk dari desa menuju kota Berastagi tersebut akan terjadi baik desa yang ditinggalkan maupun kota yang menjadi tujuan. Dampak tersebut dapat secara positif yang mendatangkan manfaat, namun dapat juga negatif. Untuk itu bik di kota maupun di desa harus dipersiapkan agar dapat mengoptimalkan dampak postif dan meminimalkan dampak negatif baik di kota maupun di desa.

\subsection{Rumusan Masalah}

Sesuai dengan Latar Belakang tersebut di atas maka Rumusan masalah dalam penelitian ini adalah sebagai berikut :

- Apa apa saja yang menjadi faktor penarik dan faktor pendorong terjadinya urbanisasi di daerah asal maupun kota Berastagi sebagai daerah tujuan,

- Bagaimana kebijakan yang dilakukan oleh pemerintah daerah Kabupaten Karo dalam mengendalikan arus urbanisasi.

\subsection{Tujuan Penelitian}

Adapun Tujuan Penelitian ini adalah untuk :

a. Menganalisis apa saja yang menjadi faktor yang menjadi Penarik dan Pendorong yang menyebabkan terjadinya urbanisasi.

b. Menganalisis upaya upaya yang dilakukan oleh pemerintah Kabupaten Karo dalam mengendalikan arus urbanisasi di daerah asal maupun di tujuan urbanisasi.

\section{TINJAUAN PUSTAKA}

\subsection{Analisis Kebijakan}

Menurut pendapat William N. Dunn (2000) bahwa analisis kebijakan merupakan suatu disiplin ilmu sosial terapan yang menggunakan berbagai jenis metode penelitian dan argumentasi untuk menghasilkan serta memindahkan suatu informasi yang relevan dengan kebijakan, sehingga dapat digunakan di tingkat politik dalam rangka memecahkan masalah.

Dilanjutkan oleh Nugroho (2014) bahwasuatu analisa kebijakan yang baik 
ialah bersifat deskriptif karena peranannya dalam memberikan rekomendasi kebijakan yang patut diambil oleh pengambil kebijakan (eksekutif).Demikian juga pengertian lain dari analisis kebijakan adalah yang dikemukakan Suharto (2010:85) yaitu sebagai usaha yang terencana dan sistematis dalam membuat analisis yang akurat mengenai konsekuensi-konsekuensi kebijakan tersebut baik sebelum maupun sesudah kebijakan tersebut diimplementasikan.

\subsection{Urbanisasi}

Banyak pengertian dari urbanisasi namun dalam penelitian ini yang utama di gunakan adalah menuru Tjiptoherijanto (2008) bahwa urbanisasi pada umumnya telah dipahami secara sebagai perpindahan penduduk dari desa ke kota meskipun sesungguhnya urbanisasi berarti persentase penduduk yang tinggal di daerah perkotaan, sedangkan perpindahan penduduk dari desa ke kota hanya salah satu penyebab proses urbanisasi. Adapun tujuan utama urbanisisi adalah mereka yang ingin mencari pekerjaan untuk memenuhi kebutuhan hidup mereka.

Dibalik tujuan baik dari urbanisasi, timbul permasalahan yaitu adanya pertambahan penduduk di kota mengakibatkan kepadatan tata ruang perkotaan. Hal ini akan berdampak pada sistem tata ruang karena banyak digunakan sebagai lahan tempat tinggal penduduk urbanisasi. Dilanjutkan oleh Evers dalam Abbas (2002) bahwa tingkat urbanisasi yang terlalu rendah akan mengabaikan kebutuhan kebutuhan kota dapat memperlambat kemajuan ekonomi, demikian juga jika terlalu besar akan berdampak berbagai ikutan negatif di kota tersebut.

\subsection{Faktor Penarik dan Pendorong}

Banyak faktor penarik dan Pendorong tentang terjadinya urbanisasi baik dari desa asal urban ataupun kota sebagai tujuan urban. Dalam Wikipedia (2011) Faktor penarik terjadinya urbanisasi secara umum urbanisasi adalah : pekerjaan di luar sektor pertanian sulit di kota banyak fasilitas kehidupan, b)ingin kehidupan yang lebih baik, c) ananfasilitas kehidupan di desa kurang, d) upah di desa masih rendah Demikian juga secara umum faktor pendorong terjadinya proses urbanisasi adalah sebagai berikut :a) lahan pertanian semakin sempit., b) merasa tidak cocok dengan budaya tempat asalnya, c) menganggur karena tidak banyak tersedia lapangan pekerjaan di desa, keterbatasan sarana dan prasarana yang dimiliki desa, d) karena sesuatu hal diusir dari desa asal, memiliki impian kuat untuk menjadi orang kaya di kota, sehingga dengan demikian dapat dikatakan bahwa urbanisasi bukan hanya terjadi di kota besar saja, tetapi di lingkup kecamatan/desa juga dapat terjadi proses pengkotaan (urbanisasi), seperti halnya di Kota Berastagi.

\subsection{Dampak Urbanisasi}

Urbanisasi akan memiliki dua mata sisi yaitu dampak negatif dan positif :Akibat negatif urbanisasi yang terjadi di desa antara lain : a) terjadi kekurangan tenaga muda karena pemuda banyak yang pindah ke kota untuk mencari pekerjaan baru, b) sulit mencari tenaga terdidik yang dijadikan sebagai tenaga penggerak dalam berbagai pembangunan sebab mereka yang mempunyai pendidikan cukup tinggi tidak lagi mau pulang ke desanya, sedangkan yang tinggal di desa sebagian besar hanyalah anak- anak dan orang tua, c) terhambatnya pembangunan di desa, d) produktivitas pertanian dan sumbersumber penghasilan di daerah pedesaan makin menurun sebab kekurangan tenaga pengelola dan d) aturan adat desa perlahan luntur.

Demikian juga halnya sebagai akibat negatif urbanisasi yang terjadi di kota antara lain :a) di bidang kependudukan, semakin meningkatnya jumlah dan penduduk di kota,b), di bidang ekonomi, kurangnya keterampilan yang dimiliki oleh urban sehingga meningkatnya pekerja 
kasar (buruh) di kota, penghidupan yang semakin sulit, kesempatan kerja juga semakin sempit, dan akhirnya jumlah pengangguran meningkat, c) di bidang sosial, jumlah perumahan yang tersedia makin sulit diperoleh sehingga timbul golongan tunawisma (gelandangan), gubuk-gubuk liar, daerah pemukiman kumuh dan lingkungan kota menjadi semeraut.

Namun demikian meskipun urbanisasi banyak membawa akibat negatif, ada juga dampak positifnya. Akibat positif urbanisasi bagi desa : a) Mengurangi pengangguran di pedesaan, b) Mengurangi kepadatan penduduk di desa, dan c) Tertanamnya sifat dinamis masyarakat desa akibat pengaruh dan urban yang pulang ke desa, sehingga menunjang pembangunan desa. Akibat positif urbanisasi bagi kota untuk memperoleh tenaga kerja yang murah untuk pembangunan, terutama tenaga kerja kasar. a) tersedianya tenaga bidang transportasi dan lain sejenisnya.

\subsection{Pengendalian Urbanisasi}

Dari aspek pemerintahan,

Kementerian dalam Negeri RI (2014) mengatakan bahwa salah satu usaha pengendalian urbanisasi adalah untuk mempercepat laju pertumbuhan ekonomi desa yang di dukung dengan pengembangan sektor pertanian, infrastrutur, pembiayaan dan sarana perekonomian seperti sarana pembibitan, paska panen dan perbengkelan.

Bukan hanya di desa tapi juga di kota pemerintah melakukan usaha untuk mengatasi berbagai akibat dari urbanisasi di kota. Usaha usaha tersebut bekerjasama dengan kementerian kementerian lainnya seperti Kementerian PUPR, Pertanian, Perhubungan, Pendidikan, Kesehatan Koperasi dan UMKM serta kementerian lainnya. Usaha tersebut anatara lain adalah : a) Menertibkan kawasan pemukiman kumuh, b) Mengadakan penghijauan kota, c) Memperluas pemukiman dengan mengadakan kawasan kota satelit, d) Menambah perumahan rakyat dengan membangun rumah murah e) Menciptakan kutub pertumbuhan baru.

\subsection{Penelitian Terdahulu}

Perkembangan kawasan perkotaan sebagaimana diungkapkan oleh Aris Pratama (2012) semakin hari semakin meningkat. Hal ini dilatarbelakangi oleh karena kawasan perkotaan menjadi magnet bagi penduduk urban untuk berdatangan mencari pekerjaan dan bertempat tinggal, sehingga jumlah penduduknya dan kepadatan semakin tinggi. Hasil analisis dari penelitian di Kota Karawang bahwa faktor-faktor peningkatan urbanisasi, yaitu perkembangan luas kawasan permukiman; jumlah penduduk; kepadatan penduduk; laju pertumbuhan penduduk (LPP); jumlah migrasi masuk; jumlah pencari kerja; nilai upah minimum regional (UMR); laju pertumbuhan ekonomi (LPE); dan tingkat perubahan mata pencaharian ke sektor sekunder dan tersier. Sedangkan faktorfaktor peningkatan perkembangan kota, yaitu keseluruhan faktor yang ada di urbanisasi ditambah dengan penurunan luas lahan pertanian; perkembangan luas kawasan industri; indeks pembangunan manusia (IPM); dan jumlah pengangguran.

Berbeda dengan Kota Karawang maka Subhan Aidit (2015) menyatakan dari hasil risetnya bahwa tahun 2015, hampir 53\% dari jumlah penduduk kota Bekasi setiap harinya melakukan aktivitas di Jakarta pada pagi dan kembali ke Kota Bekasi di malam harinya. Aktivitas dominan yang umum terjadi dilakukan oleh para commuter ini untuk kegiatan bekerja dan sekolah. Aktivitas kaum migran yang melakukan pergerakan dari wilayah pinggiran ke kota induk dapat dikelompokkan sebagai migrasi ulang alik. Faktor Pendorong dan Penarik Penduduk Migran Kota Bekasi ulak-ulik yaitu pergerakan yang dilakukan oleh migran dengan tidak ada niatan untuk menetap di wilayah tujuan dan dilakukan secara rutin dalam jangka waktu yang pendek dan dapat terjadi dalam satu hari. 


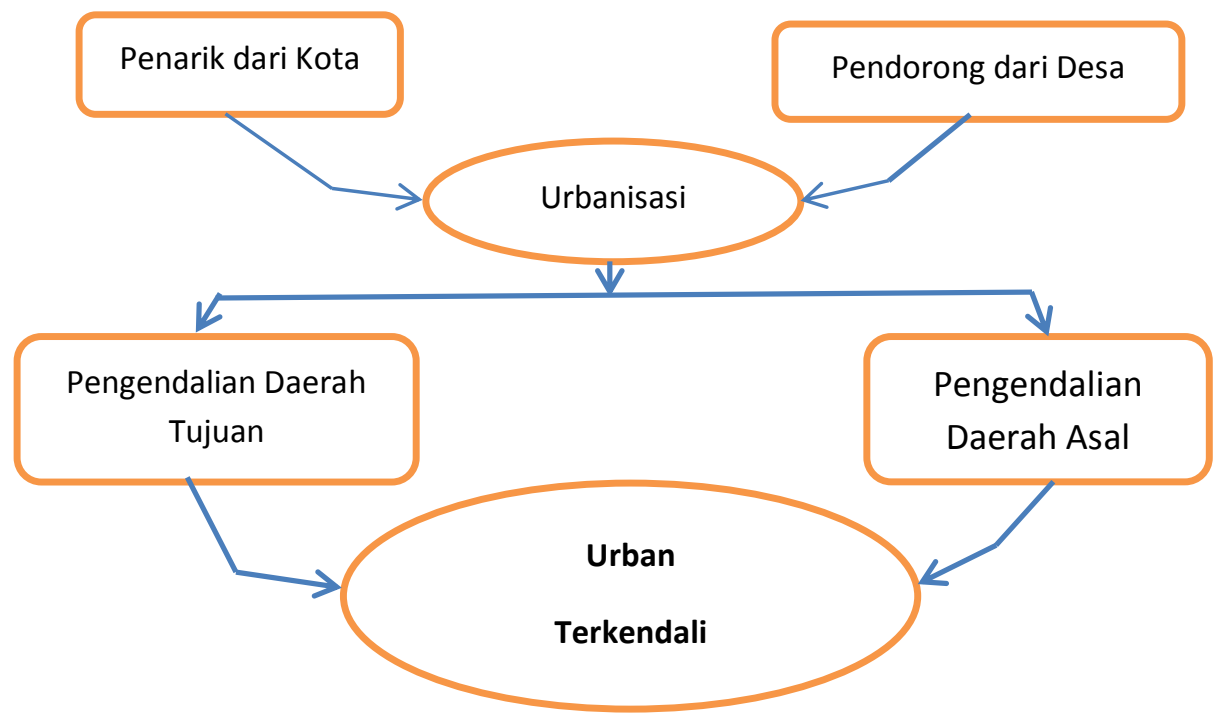

Gambar 1. Kerangka Pikiran oleh peneliti, 2020

\section{METODE PELAKSANAAN}

\subsection{Metode}

Metode yang digunakan dalam penelitian ini adalah Diskriptif Kualitatif yaitu yang memberikan gambaran maupun identifikasi berdasarkan data-data yang bersifat kualitatif. Nazir (2003) menjelaskan bahwa metode deskriptif bukan hanya memberikan gambaran akan tetapi menerangkan hubungan, membuat prediksi serta mendapatkan makna dan implikasi dari suatu masalah yang ingin diselesaikan.

\subsection{Jenis dan Sumber Data}

Jenis dan Sumber data terdiri dari dua jenis yaitu jenis dan Sumber Data Primer yang di kumpulkan melalui wawancara baik dengan Informan Kunci maupun pendukung, dan observasi lapangan sedangkan jenis dan sumber Data Sekunder adalah dari litratur, media masasa, serta dokumentasi dari berbagai isntansi yang terkait.

\subsection{Teknik Pengumpulan Data}

Wawancara yaitu pengumpulan data dengan wawancara pihak yaitu : informan kunci yaitu pejabat yang berkompeten dan berkewenangan dalam pengambilan kebijakan anatara lain : a) Kepala Bappeda Kabupaten Karo,b) Kepala Dinas Kimpraswil, c) Kepala Dinas Sosial dan Tenaga Kerja atau dengan staf yang membidangi, d) Disamping dengan informan kunsci maka di lakukan juga wawancara dengan informan pendukung : e) Camat, f) Lurah dan g) Kepala Lingkungan serta personil lain yang dianggap mumpuni dalam memberikan keterangan. Wawancara di lakukan secara terbuka tanpa menggunakan kuesioner. Disamping wawancara maka di wilayah penelitian dilakukan juga observasi (pengamatan) di lapangan khususnya klaster urban urban di kota BerastagiStudi Litratur dari buku, jurnala an media, Studi Dokumentasi baik berupa laporan, audio visual dan lain sejenisnya.

\subsection{Analisis Data}

Metode yang di gunakan dalam penelitian ini bersifat deskriftif kualitatif dengan Analisa Kualitatifi yaitu :a) mempelajari tentang faktor faktor penarik dan 
pendorong terjadinya urbanisasi, b) Analisis Diskriftif yaitu upaya upaya yang dilakukan Pemerintah Kabupaten Karo dalam pengendalian urbanisasi baik di daerah asal maupun tujuan, c) analisis Kebijakan Implementasi Pengendalian Urbanisasi di Kota Berastagi.

\section{HASIL DAN PEMBAHASAN}

\subsection{Penyebab Urban}

Sebelum membahas tentang penyebab terjadinya urban, dampak yang ditimbulkan urban serta kebijakan pengendalian, sebelumnya di bahas dulu tentang karakteristik urban di Kabupaten Karo khususnya di Kota Berastagi.

\subsubsection{Pendorong dari Desa}

Hasil penelitian ini menunjukkan bahwa berdasarkan observasi lapangan dan wawancara yang dilakukan dengan baik dengan informan utama dalam hal ini staf bappeda Karo yang menangani masalah pedesaan dan informan pendukung yaitu urban yang ada di kota berastagi yang dilakukan secara acak di 3 komoiitas urban yaitu :

a. Wilayah (zona) I adalah di Jl. Udara Berastagi mulai dari Tugo Kol ke arah Kecamatan Simpang Empat.

b. Wilayah (zona) II adalah Jalan Jamin Ginting dari Tugo Kol ke arah Kecamatan Kaban Jahe dan,

c. Wilayah III (zona) III yaitu dari Tugu Mejuah Juah ke arah Taman Hutan Rakyat (Tahura).

Faktor Pendorong utama urban dari daerah asal bagi yang Belum Berkeluarga adalah Malu Tinggal di Desa sedangkan bagi yang Sudah Berkeluarga adalah Terbatasnya Lapangan Kerja di Desa menunjukkan bahwa terdapat kesenjangan pembangunan anatara daerah asal di desa mereka dengan pembanguanan Kota Berastagi sebagai pusat kota pemerintahan, pariwisata, jasa dan perdagangan telah mendorong mereka untuk meninggalkan desa.
Dari hasil wawancara dengan para informan tambahan yaitu lurah dan kepala desa yang ada di sekitar Kota Berastagi seperti kepala desa Raya, lurah Gundaling I dan II yang di di wilayahnya banyak tinggal kaum urban tersebut menambahkan bahwa keterbatasan yang dimiliki desa dalam menyedikan lapangan kerja adalah menjadi faktor pendorong utama bagi kaum urban untuk meninggalkan desa masing masing menuju ke Kota Berastagi. Memang ada alasan lain seperti minimnya failitas umum di desa seperti fasilitas pendidikan dan kesehatan juga menjadi alasan yang cukup kuat.

\subsubsection{Penarik dari Kota}

Berdasarkan observasi lapangan bahwa komonitas urban di Berastagi yang bekerja di sektor Pertanian sekitar Jalan Udara Tugu Kol Berastagi, sektor Perkantoran sekitar jalan Djamin Ginting mulai dari komplek kantor Bupati Karo menuju Tugu Tol Berastagi maupun sektor dari Tugu Mejuah juah Berastagi ke Taaman Hutan rakyat Berastagi meunjukkan bahwa terdapat juga alasan utama yang belum berkeluarga aalah memiliki teman baru sedangkan yang sudah berkeluarga adalah upah yang lebih tinggi.

\subsection{Dampak Urban}

\subsubsection{Dampak di Desa}

Dari Informan pendukung staf yang membidangi pemberdayaan masyarakat desa dan juga dari staf Dinas Tenaga Kerja Kabupaten Karo bahwa Urban di desa desa Kabupaten Karo yang umumnya ke Kaban Jahe dan Berastagi dalam lingkup Kabupaten Karo dan keluar dari Tanah Karo umumnya menuju Medan, Batam, Jawa dan kota kota lainnya yang sebagian besar di Pulau Sumatera dan Jawa telah menunjukkan dampak Positif dan Negatif yang Utama dan Dampak lainnya. 
Tabel 1. Dampak Positif dan Negatif Urban di Desa, 2020.

\begin{tabular}{|l|l|l|}
\hline No. & \multicolumn{1}{|c|}{ Utama } & \multicolumn{1}{c|}{ Dampak lainnya } \\
\hline Dampak Positif & $\bullet \begin{array}{l}\text { berkurangnya } \\
\text { pengangguran } \\
\text { berkurangnya } \\
\text { kriminalitas }\end{array}$ & $\begin{array}{l}\text { Adanya aliran dana dari urban ke } \\
\text { desa }\end{array}$ \\
\hline Dampak Negatif & $\bullet \quad \begin{array}{l}\text { sulitnya tenaga kerja } \\
\text { semakin tinggi upah TK }\end{array}$ & $\begin{array}{l}\text { dampak terhadap keluarga yang } \\
\text { di tinggalkan (bagi yang sudah } \\
\text { berkeluarga) }\end{array}$ \\
\hline
\end{tabular}

Sumber : hasil wawancara dengan Informan Tambahan, 2020

Berdasarkan keterangan keterangan yang di peroleh dari Informan utama maupun Pendukung melalui analisis Delphi yaitu menselaraskan dengan observasi lapangan dan Study Litratur yang di gunakan maka peneliti menemukan ada dua dampak positif urban yang utama bagi desa yaitu berkurangnya pengangguran dan berkurangnya tingkat kriminalitas.

\subsubsection{Dampak di Kota Berastagi}

Dari hasil Analisis Delphi yang di lakukan oleh peneliti terhadap Informan Kunci maupun pendukung maka dampak Positif dan Negatif dari adanya Urbanisasi terhadap Kota Berastagi adalah sebagai berikut :

Tabel 2. Dampak Urban bagi Kota Berastagi, 2020

\begin{tabular}{|c|c|c|}
\hline No, & Utama & Dampak lainnya \\
\hline Dampak Positif & 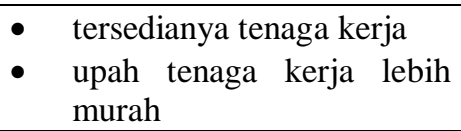 & $\begin{array}{l}\text { - Meningkatnya perekonomian } \\
\text { sektor informal }\end{array}$ \\
\hline Dampak Negatif & $\begin{array}{ll}\text { - } & \text { bertambahnya perumahan } \\
\text { kumuh } \\
\text { - } \\
\text { semakin sempitnya ruang } \\
\text { terbuka hijau } \\
\text { - meningkatnya kriminalitas }\end{array}$ & $\begin{array}{ll}\text { - } & \text { bertambahnya bangunan liar di } \\
\text { ruang publik } \\
\text { - } \\
\text { kemacaten lalu lintas pada jam } \\
\text { tertentu } \\
\text { - } \\
\text { meningkatnya polusi udara }\end{array}$ \\
\hline
\end{tabular}

Sumber : hasil wawancara dengan Informan Tambahan, 2020

Dari hasil wawancara dengan informan utama yaitu Dinas Tarukim dan Dinas Tenaga Kerja dan Koperasi Kabupaten Karo maupun obsevasi lapangan menunjukkan setidaknya ada dua dampak positif dari kehadiran para urban yaitu a) tersedianya tenaga kerja dan b) upah tenaga kerja yang lebih murah. Sedangkan dampak tambahan lainnya adalah meningkatnya perekonomian sektor informa,

\subsection{Upaya Pemerintah \\ 4.3.1 Upaya di Kota}

Berbagai upaya pemerintah di Kota Berastagi dalam rangka pengendalian urbanisasi ini antara lain adalah : a. Penyelengaraan

Regristrasi Penduduk.

Dari hasil wawancara dengan staf di Dinas Catatan Sipil dan Kependudukan Kabupaten Karo bahwa salah satu kesulitan dari kaum urban ini karena setatus mereka yang masih tetap terregristrasi di desa masing masing walaupun mereka sudah lama menetap di kota Berastagi.

b. Rencana Zona Pemukiman

Disamping upaya regristrasi penduduk untuk pengendalian urban yang ada di Kota Berastagi juga di perlukan perencanaan untuk menata kota Berastagi yang pertumbuhannya terkendali dengan ruang yang dapat meminimalisasi dampak dampak 
negatif pertumbuhan kota.

Berdasarkan fakta lapangan tentang konsentrasi secara umum pemukiman kaum urban maka pada prinsipnya ide tenatang zonasi urban mendapat tanggapan positif dari Ketua Bappeda Karo dan juga Kepala Dinas Tarukim Kabupaten Karo. Konsep ini tentu menjadi bahan masukan bagi Pemerintah Kabupaten Karo dan perlu di bicarakan dengan DPRD dan meminta masukan dari setiap Stakeholder.

Adapun zonasi tersebut adalah sepanjang jalan udara dari Tugu Kol Berastagi di dominasi oleh gudang gudang hasil pertanian mulai dari kecil sampai besar. Sepanjang Jl. Kaban jahe Berastagi di padati oleh sarana perkantoran dan pemukiman serta dari tugu Beras Tagi sampai ke Tahura merupakan kawasan agrowisata yang semua menjadi daya tarik masyarakat desa tsekitarnya baik di Kecamatan Berastagi, Simpang Empat, Naman Teran, Merdeka dan Dolat Rakyat.

\subsubsection{Dampak di Kota}

a. Dampak Positif

Dapat di pastikan jika tidak ada upaya pengendalian yang terus menerus dilakukan maka dampak dampak yang di timbulkan yaitu dampak negatif semakin besar demikian juga jika upaya upaya pengendalian berhasil dengan baik maka arus urbanisasi tersebutpun akan berdampak terhadap kemajuan ekonomi kota dan Berastagi menjadi kota idaman bagi warganya antara lain tersedianya tenaga kerja dalam jumlah yang memadai, upah relatif lebih murah dan lain sebagainya.

b. Dampak Negatif

Jika tidak ada pengendalian urban dari desa serta pembenahan pembenahan di lakukan di kota maka urbanissasi membawa dampak di Kota Berastagi anataralai tingginya kepadatan penduduk khususnya di pemukiman urban, meningkatnya kebutuhan akan sarana umum seperti air minum. Listrik fasilitas kesehatan dan pendidikan, meningkatnya tingkat kriminalitas sebagai akibat kegiatan illegal perjudian, miras dan penyakit sosial lainnya.

\subsubsection{Upaya di Desa}

Berbagai kebijakan yang di tempuh dalam pengendalian urban di daerah asal antara lain adalah : a) melaksanakan pembangunan dengan cara desentralisasi, b) melakukan modernisasi desa melalui progam-progam pembangunan yang dirancang sesuai dengan kebutuhan desa, c) meningkatkan angka fasilitas yang dibutuhkan masyarakat desa, mulai dari pendidikan, kesehatan, sarana hiburan, hingga transportasi, d) mengendalikan pertumbuhan pada masyarakat pedesaan melalui program-program KB (Keluarga Bencana). e) meningkatkan angka perekonomian di desa, f) mengeluarkan peraturan yang bisa mempersulit masyarakat desa yang ingin berpindah ke kota dan g) meningkatkan keamanan di wilayah desa dengan mengaktifkan sistem keamanan lingkungan yang lebih baik.

Hal yang tidak kalah penting adal senantiasa meningkatkan sumber sumber penerimaan keuangan untuk pembanguan desa yang antara lain adalah : a) Alokasi dana Desa (ADD), b0 Anggaran pendapatan dan Belanja (APBD) Kabupaten Karo, c) Bantuan Modal Kerja serta partispasi pembangunan dari pihak ke tiga yang tidak mengikat.

\section{SIMPULAN}

a. Faktor Pendorong utama urban dari daerah asala bagi yang Belum Berkeluarga adalah Malu Tinggal di Desa sedangkan bagi yang Sudah Berkeluarga adalah Terbatasnya Lapangan Kerja di Desa.

b. Faktor Penarik utama urban dari daerah tujuan adalah bagi yang Belem Berkeluarga adalah Ajakakan teman yang sudah ada di kota sedangkan bagi yang Sudah 
Berkeluarga adalah Mencari Pekerjaan Baru.

c. Upaya yang di lakukan Pemerintah di Daerah Asal adalah Mendorong dan Memfasilitasi : Pinjaman Lunak, Bantuan Program Pemberdayaan UMKM (khususnya Usaha Mikro) Dan Membangun Fasilitas desa melalui APBD.

d. Upaya yang dilakukan Pemerintah di daerah tujuan urbanisasi Kota Berastagi adalah Membuat Rencana Pemukiman baru yang terdiri dari a. Zona Pertanian di Jl. Udara (Tugu Kol ke arah Kecamatan Simpang Empat); b. Zona Perkantoran Di Jl. Djamin Ginting (dari Tugu Kol menuju Kec. kaban Jahe); . dan c. Zona Pariwisata Jl. Djamin Ginting mulai Tugu mejuah Juah menuju Tahura)

\section{Saran}

a. Pemerintah agar segera mengadakan pendataan terhadap urban khususnya yang tidak menetap tinggal di Berastagi,

b. Menjejaki adanya areal pemukiman bagi warga urban yang berdekatan dengan konsentarsi kerja yaitu Urban Pertanian sekitar J1. Udara menuju Kec. Simpang Empat; Urban Perkantoran sekitar JL. Djamin Ginting menuju Kecamatan Kaban Jahe, serta Urban Pariwisata Jl. Djamin Ginting menuju Taman Hutan rakyat (Tahura)

\section{DAFTAR PUSTAKA}

Adisasmita (2006) Adisasmita, Raharjo. 2006. Pembangunan Pedesaan dan Perkotaan. Graha ilmu. Yogyakarta.

Agustan (2012) Merantau: Studi tentang Fktor Pendorong dan dampak Sosial Ekonomi Terhadap Aktivitas Merantau di Desa Sijelling Kecamatan Tellu Siattinge kabupaten Bone. Program Studi Sosial Politik Universitas Negeri Maksar. Makassar.

Arikunto, Suharsimi, 1996, Dasar-dasar Evaluasi, Rineka, Jakarta.

Arikunto, Suharsimi, 1991, Prosedur Penelitian Suatu Pendekatan Praktek. Rineka Cipta. Jakarta,

Aris Pradana (2012) Identifikasi Pengaruh Peningkatan Urbanisasi Terhadap Perkembangan Kota di Kawasan Perkotaan Karawang. Thesis, Fakultas Teknis Pasundan Karawang.

Direktorat jenderal Cipta Karya Kementerian Kimpraswil 2016. Lapran Konerja 2016. Media Pertanggungjawaban Pelaksanaan Program dan Kegiatan Unit Organisasi. Jakarta 2016.

Fahmi Ardiansyah (2018). Urbanisasi dan Ketimpangan Kebijakan. Kompasiana. Jakarta.

Firman, H \& Widodo A. (2007) Bukti Panduan Pendidikan Ilmu Pengetahuan Alam. Pusat Perbukuan. Kementerian Pendidikan Nasional Jakarta. 2010.

Ratna Suminar. 2015. Koordinasi Antar Instansi Pemerintah Kota BandarLampung Dalam Pelaksanaan Program Pengembangan Kota Hijau. Bandar Lampung: Universitas Lampung. Faktor Pendorong Dan Penarik Penduduk Migran Kota Bekasi Ke Jakarta.

Rivan Tri Youono (2012) Pengendalian Urbanisasi untuk Perbaikan Tata Ruang Kota. Artikel Komasiana. Jakarta.

Subhan Adi A, Nanik Istiyani1, Andjar Widjajanti Jurusan Ekonomi Pembangunan, Fakultas Ekonomi dan Bisnis, Universitas Jember.

Suharto, Edi. 2010. Analisis Kebijakan Publik . CV Alfabeta. Bandung 
Sugiyono. 2009. Metode Penelitian kuantitatif dan kualitatif dan RnD. Alfabeta. Bandung

Sugiyono. 2012. Metode Penelitian Administrasi. CV Alfabeta. Bandung

Tjiptoherijanto. 2000. Mobilitas Penduduk dan Pembangunan Ekonomi, Naskah No.20, Juni-Juli 2000.

Tjiptoherijanto. 2000. Urbanisasi dan Perkembangan Perkotaan di Indonesia, http://www.geocities.com/nuds2/18html.

(Mei, 2000)

Undang - Undang Nomor 26 Tahun. 2007 tentang Tata Ruang. Lembaran Negara Republik Indonesia Tahun 2010. Jakarta.

Yunus, Hadi Sabari. 2010. Metodelogi Penelitian Wilayah Kontemporer. Yogyakarta:Pustaka Pelajar. 